\title{
Influence of a Cylindrical Thermally-Conductive Inclusion on the Heat Flow through the Light Building Envelopes
}

\author{
Konstantin Afonin ${ }^{1}$, Tatyana Zhilina ${ }^{1, *}$, Anatoly Shapoval ${ }^{1}$, and Boris Moiseev ${ }^{1}$ \\ ${ }^{1}$ Industrial University of Tyumen, 625001 Volodarskogo str. 38, Tyumen, Russia
}

\begin{abstract}
Paper introduces a mathematical model describing the distribution of temperature field around the cylindrical thermallyconductive inclusion. It also presents an experimental setup based on REOCAMTCM-1000 climate chamber, as well as the obtained results of the temperature distribution on the surface of a light building envelope under the influence of a cylindrical thermally-conductive inclusion.
\end{abstract}

\section{Introduction}

Western Siberia has all kinds of fuel and energy resources and is a major oil and gas producing region. Fuel and energy complex of Western Siberia is one of the main factors of the country economy development. When considering the development of the North, one should consider its specific features:

- distance from developed regions of the country,

- absence of a stable transport links within the area and of the developed construction materials industry,

- random placement of its plants,

- high labor costs.

Harsh climatic conditions of the North, marked by low outside temperatures, large diurnal changes in temperature, strong winds, snow drifts and intense rains, make it necessary to consider all these factors in the design and construction of buildings [1].

Construction in the North is imposed with strict requirements defining the appropriate indoor climate, provision of the essential conveniences for living, as well as economic indicators - reducing the labor intensity, increasing the level of industrialization of construction, lasting quality, reduction of capital and operational costs. Climatic region of construction largely determines the requirement for a reliable thermal protection of buildings and provision of a comfortable microclimate in residential facilities in the North $[1,2]$.

The main direction of the industrialization of the oil and gas extraction facilities arrangement is a factory-assembled method, which is indispensable in the construction of energy complex surface facilities in the northern regions of Western Siberia [3].

* Corresponding author: tgasu.zhilina.tatyana@mail.ru 
Oil and gas facilities refer to the small-volume and distributed objects, which are currently built in factory-assembled way. Outer light envelopes are constructed of metal panels with an effective insulation $[4,5]$.

The main feature of light envelopes is the necessity to study their properties over time, due to presence of thickening, which eventually leads to a loosening of the hermetic sealing and increase of the air permeability through the outer envelopes and as a result - to increase of the energy consumption for climate control.

Due to specific design features, zones with different thermally-conductive inclusions occur in building envelopes. They can be through, perforated, etc., and have different shapes. In northern conditions there is a presence of a large temperature gradient between the outer and inner walls of the building envelope. The combination of the temperature gradient and specific design features cause the heavy increase of heat loss and breach of the facility comfort conditions.

\section{Subjects and methods}

The authors analyze the distribution of temperature field around the cylindrical thermallyconductive inclusion $[6,7,8]$.

Figure 1 presents the scheme that has been selected for calculation the stationary distribution of thermal field on the building envelope surface, containing thermallyconductive inclusion of cylindrical shape.

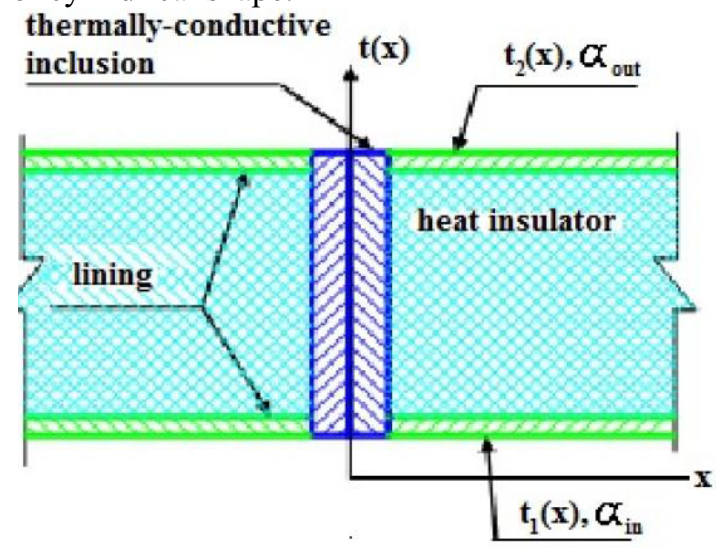

Fig. 1. Scheme of the cylindrical thermally-conductive inclusion.

Building envelope consists of two metal layers between which there is a layer of material with high thermal resistance. The envelope parameters are going to be designated as following:

- $\delta_{1}, \delta_{2}$ - thickness of the inner and outer lining,

- $R_{0}$ - thermal resistance of the lining material,

- $R$ - thermal resistance of the thermally-conductive inclusion,

- $t_{\text {in }}, t_{\text {out }}$ - indoor and outdoor air temperature,

- $\alpha_{i n}, \alpha_{o u t}, \lambda_{1}, \lambda_{2}$ - coefficients of surface heat exchange and thermal conductivity for inner and outer surfaces accordingly,

- $r_{0}$ - radius of the thermally-conductive inclusion.

If we consider the problem as the spatial one, there arises a problem of solution of the Laplace's equation with various spatial physical properties which makes it necessary to reconcile the obtained results in different areas with one another. This leads to unnecessary complication of the solving the problem process. 


\section{TPACEE-2016}

The authors put forward a different approach. Its feature is that the temperature distribution inside the envelope layer is not so significant when calculating of heat loss through this structure. Temperature fields on the mating surfaces, which are involved in major heat exchange, are more important. Spatial temperature distribution along the $Z$ axis and the angular dependence are also ignored, as the problem has cylindrical symmetry by condition $[6,9,10]$. For example, to balance the heat flow in a cylindrical reference frame, we get the following equation in partial derivatives $[11,12]$

$$
\frac{\partial^{2} \mathrm{t}}{\partial \mathrm{r}^{2}}+\frac{\partial \mathrm{t}}{\mathrm{r} \partial \mathrm{r}}+\frac{\partial^{2} \mathrm{t}}{\mathrm{r}^{2} \partial \theta^{2}}+\frac{\partial^{2} \mathrm{t}}{\partial \mathrm{z}^{2}}=0
$$

where $t(r, \theta, z)=t(M)$ - temperature at any point of the envelope.

If we get down to the description of the heat flow based on the assumptions for inner and outer surfaces of the envelope set out above, the following components can be defined. Let us assume that $t_{l}(r)$ - temperature distribution on the inner surface of the envelope, and $t_{2}(r)$ - temperature distribution on the outer surface of the envelope.

Then:

$\frac{d^{2} t_{1}}{d r^{2}}+\frac{d t_{1}}{r d r}$ - reduced density of a heat flow distributing along the uniform inner surface;

$\frac{\alpha_{i n}}{\lambda_{1} \delta_{1}}\left(t_{i n}-t_{1}\right)-$ reduced density of a heat flow ingoing due to a heat exchange between surface and environment;

$\frac{t_{1}-t_{2}}{\lambda_{1} \delta_{1} R_{o}}$ - reduced heat flow, outgoing from the surface due to flows through the material inside the envelope.

Taking into account these flows, differential equations for each of the surfaces can be written. For further convenient manipulations, we introduce the following designations:

$$
\begin{gathered}
m_{1}=\frac{\alpha_{\text {in }}}{\lambda_{1} \delta_{1}} ; n_{1}=\frac{\alpha_{\text {out }}}{\lambda_{2} \delta_{2}} ; m_{o}=\frac{1}{R_{o} \lambda_{1} \delta_{1}} ; n_{o}=\frac{1}{R_{o} \lambda_{2} \delta_{2}} ; m_{10}=m_{1}+m_{0} ; n_{10}=n_{1}+n_{0} ; \\
p_{11}=\frac{r_{0}}{2 \lambda_{1} \delta_{1}}\left(\alpha_{\text {in }}+\frac{1}{R}\right) ; p_{22}=\frac{r_{0}}{2 \lambda_{2} \delta_{2}}\left(\alpha_{\text {out }}+\frac{1}{R}\right) ; \\
p_{12}=\frac{-r_{0}}{2 R \lambda_{1} \delta_{1}} ; p_{21}=\frac{-r_{0}}{2 R \lambda_{2} \delta_{2}} ; q_{1}=-\frac{\alpha_{\text {in }} r_{0} t_{\text {in }}}{2 \lambda_{1} \delta_{1}} ; q_{2}=-\frac{\alpha_{\text {out }} r_{0} t_{\text {out }}}{2 \lambda_{2} \delta_{2}}
\end{gathered}
$$

Using new designations the system of equations for determining the temperature fields will be presented as follows:

$$
\begin{aligned}
& \frac{d^{2} t_{1}}{d r^{2}}+\frac{d t_{1}}{r d r}-m_{10} t_{1}+m_{0} t_{2}+m_{1} t_{\text {in }}=0 \\
& \frac{d^{2} t_{2}}{d r_{2}}+\frac{d t_{2}}{r d r}-n_{10} t_{2}+n_{0} t_{1}+n_{1} t_{\text {out }}=0
\end{aligned}
$$

where $t_{1}(r)$ and $t_{2}(r)$ enter each equation symmetrically. Determination of their functional dependence is interrelated.

Boundary conditions along the boundary of a thermally-conductive inclusion with radius $r_{0}$ and thermal resistance $R$ can be written as follows: 


$$
\begin{aligned}
& \lambda_{1} \delta_{1} 2 \pi r_{0} \frac{d t_{1}}{d r}+\alpha_{\text {in }} \pi r_{0}\left(t_{\text {in }}-t_{1}\right)=\frac{t_{1}-t_{2}}{R} \pi r_{0}^{2} \\
& -\lambda_{2} \delta_{2} 2 \pi r_{0} \frac{d t_{2}}{d r}+\alpha_{\text {out }} \pi r_{0}{ }^{2}\left(t_{2}-t_{\text {out }}\right)=\frac{t_{1}-t_{2}}{R} \pi r_{0}^{2}
\end{aligned}
$$

In this equation, the first term is associated with the description of amount of heat outgoing to the surface due to heat exchange along the boundary of a thermally-conductive inclusion, the second term describes the loss of heat due to heat exchange between the surface of a thermally conductive inclusion with the outer air. The right side of the equation presents the heat flow going through the thermally-conductive inclusion from one side of the surface to another with a thermal resistance $R$, area $\pi r_{0}{ }^{2}$ with the temperature difference $t_{1}-t_{2}$.

For the equations describing the boundary conditions for the temperature fields in new designations we get the following system:

$$
\begin{aligned}
& \left.\frac{d t_{1}}{d r}\right|_{r=r_{0}}=p_{11} t_{1}+p_{12} t_{2}+q_{1} \\
& \left.\frac{d t_{2}}{d r}\right|_{r=r_{0}}=p_{21} t_{1}+p_{22} t_{2}+q_{2}
\end{aligned}
$$

The solution of the initial system of equations (and each of them is the Bessel equation) can be found in the form of a linear combination of Macdonald functions, bounded at infinity, modifications of Bessel functions $[13,14]$. To eliminate the constant component in each of the equations (4), we will seek the solution in the following form:

$$
\begin{aligned}
& t_{1}=t_{10}+t_{1}^{*}(r) \\
& t_{2}=t_{20}+t_{2}{ }^{*}(r)
\end{aligned}
$$

After substituting the equations solutions of this form into the equations of the system (4) and setting the constant component of each equation to zero, we obtain the following system of equations for determining the constant components $t_{10}$ and $t_{20}$ :

$$
\begin{aligned}
& -m_{10} t_{10}+m_{0} t_{20}+m_{1} t_{\text {in }}=0 \\
& -n_{10} t_{10}+n_{0} t_{20}+n_{1} t_{\text {out }}=0
\end{aligned}
$$

After applying the corresponding quantities instead of the previously introduced designations (2) and after solving the received system (7), we obtain the corresponding values for these constants:

$$
\begin{aligned}
& t_{10}=t_{\text {in }}-\frac{t_{\text {in }}-t_{\text {out }}}{1+R_{0} \alpha_{\text {in }}+\frac{\alpha_{\text {in }}}{\alpha_{\text {out }}}} \\
& t_{20}=t_{\text {out }}+\frac{t_{\text {in }}-t_{\text {out }}}{1+R_{0} \alpha_{\text {out }}+\frac{\alpha_{\text {out }}}{\alpha_{\text {in }}}}
\end{aligned}
$$




\section{TPACEE-2016}

The variable component of the temperature field $t_{1}{ }^{*}(r)$ и $t_{2}{ }^{*}(r)$ will be sought in the following form:

$$
\begin{aligned}
& t_{1}^{*}=A_{11} K_{0}\left(v_{1} r\right)+A_{12} K_{0}\left(v_{2} r\right) \\
& t_{2}{ }^{*}=A_{21} K_{0}\left(v_{1} r\right)+A_{22} K_{0}\left(v_{2} r\right)
\end{aligned}
$$

In these equations $A_{i j}$ and $v_{i}$ are undetermined constants that will be chosen to satisfy both the equations (3) and the boundary conditions (4). $K_{0}\left(v_{i} r\right)$ function is a Macdonald function of zero order. After applying the solution (9) into the first equations of the system (4), we obtain:

$$
\begin{aligned}
& A_{11}\left(\frac{d^{2} K_{0}\left(v_{1} r\right)}{d r^{2}}+\frac{1}{r} \cdot \frac{d K_{0}\left(v_{1} r\right)}{d r}-v_{1}^{2} K_{0}\left(v_{1} r\right)\right)+A_{11} v_{1}^{2} K_{0}\left(v_{1} r\right)+ \\
& +A_{12}\left(\frac{d^{2} K_{0}\left(v_{2} r\right)}{d r^{2}}+\frac{1}{r} \cdot \frac{d K_{0}\left(v_{2} r\right)}{d r}-v_{2}^{2} K_{0}\left(v_{2} r\right)\right)+A_{12} v_{2}^{2} K_{0}\left(v_{2} r\right)-m_{10} A_{11} K_{0}\left(v_{1} r\right)-m_{10} A_{12} K_{0}\left(v_{2} r\right)+ \\
& +m_{0} A_{21} K_{0}\left(v_{1} r\right)+m_{0} A_{22} K_{0}\left(v_{2} r\right)=0
\end{aligned}
$$

We obtained equations in brackets with coefficients $A_{11}$ and $A_{12}$. Macdonald functions satisfy these equations, so these terms of equations become zero. By combining the remaining terms, we obtain:

$$
\left(A_{11}\left(v_{1}^{2}-m_{10}\right)+A_{21} m_{0}\right) K_{0}\left(v_{1} r\right)+\left(A_{12}\left(v_{2}^{2}-m_{10}\right)+A_{22} m_{0}\right) K_{0}\left(v_{2} r\right)=0
$$

By requiring coefficients to become zero in ahead of the Macdonald functions in this equation, we get:

$$
\begin{aligned}
& A_{11}\left(v_{1}^{2}-m_{10}\right)+A_{21} m_{0}=0 \\
& A_{12}\left(v_{2}^{2}-m_{10}\right)+A_{22} m_{0}=0
\end{aligned}
$$

The received requirement means that there is a link between the coefficients included in the solution. The link is determined by the equation, that is:

$$
\begin{aligned}
& A_{21}=-A_{11} \frac{v_{1}^{2}-m_{10}}{m_{0}} ; \\
& A_{22}=-A_{12} \frac{v_{2}^{2}-m_{10}}{m_{0}} .
\end{aligned}
$$

This means that we can seek the solution to this equation for the same constant values $v$, but with different coefficients, namely:

$$
\begin{aligned}
& t_{1}^{*}=C K_{0}(v r) ; \\
& {t_{2}}^{*}=D K_{0}\left(\begin{array}{rr}
v & r
\end{array}\right) .
\end{aligned}
$$

We use this type of solution (14) in both equations (4) and obtain:

$$
\begin{aligned}
& C v^{2} K_{0}(v r)-m_{10} C K_{0}(v r)+m_{0} D K_{0}(v r)=0 ; \\
& D v^{2} K_{0}(v r)-n_{10} D K_{0}(v r)+n_{0} C K_{0}(v r)=0
\end{aligned}
$$

Or 


$$
\begin{aligned}
& \left(C\left(v^{2}-m_{10}\right)+D m_{0}\right) K_{0}(v r)=0 \\
& \left(D\left(v^{2}-n_{10}\right)+C n_{0}\right) K_{0}(v r)=0 .
\end{aligned}
$$

From the condition of equation satisfaction it follows that the coefficient ahead of the function $K_{0}(v r)$ must become zero. Therefore:

$$
\begin{aligned}
& C\left(v^{2}-m_{10}\right)+D m_{0}=0 \\
& D\left(v^{2}-n_{10}\right)+C n_{0}=0 .
\end{aligned}
$$

The received system of equations is homogeneous and has non-zero solutions only if determinant of the system becomes zero. Then:

$$
\left|\begin{array}{cc}
v^{2}-m_{10} & m_{0} \\
n_{0} & v^{2}-n_{10}
\end{array}\right|=0 .
$$

By expanding the determinant, we obtain a biquadratic equation as regard to $v$, or

$$
v^{4}-v^{2}\left(m_{10}+n_{10}\right)+\left(m_{10} \cdot n_{10}-m_{0} \cdot n_{0}\right)=0
$$

Positive roots of this equation can be presented in the following form:

$$
v_{1,2}=\sqrt{\frac{\left(m_{10}+n_{10}\right) \pm \sqrt{\left(m_{10}-n_{10}\right)^{2}+4 m_{0} n_{0}}}{2}} .
$$

From the analysis of the values included in this determinant, we can get some useful relations:

$$
\left(v^{2}-m_{10}\right)\left(v^{2}-n_{10}\right)-m_{0} n_{0}=0 \Rightarrow \frac{v_{1,2}^{2}-m_{10}}{m_{0}}=\frac{n_{0}}{v_{1,2}^{2}-n_{10}} .
$$

After introducing the auxiliary constants $M$ and $N$, the relations between them will be presented in the following form:

$$
\begin{aligned}
& M=\frac{m_{10}-v_{1}^{2}}{m_{0}}=\frac{n_{0}}{n_{10}-v_{1}^{2}} ; N^{-1}=\frac{m_{10}-v_{2}^{2}}{m_{0}}=\frac{n_{0}}{n_{10}-v_{2}^{2}} ; \\
& \frac{M}{N}=\frac{m_{10}-v_{1}^{2}}{m_{0}} \cdot \frac{n_{0}}{n_{10}-v_{2}^{2}}=\frac{m_{10}-v_{1}^{2}}{m_{0}} \cdot \frac{n_{0}}{n_{10}-m_{10}-n_{10}+v_{1}^{2}}=-\frac{n_{0}}{m_{0}},
\end{aligned}
$$

where the relation between the roots of a quadratic equation $v_{1}^{2}+v_{2}^{2}=m_{10}^{2}+n_{10}^{2}$ is used.

Using the relation between the coefficients for the desired solution, we can now present the desired solution in the following form:

$$
\begin{aligned}
& t_{1}=t_{10}+A_{11} K_{0}\left(v_{1} r\right)+N A_{22} K_{0}\left(v_{2} r\right) ; \\
& t_{2}=t_{20}+M A_{11} K_{0}\left(v_{1} r\right)+A_{22} K_{0}\left(v_{2} r\right) .
\end{aligned}
$$

The remaining unknown coefficients of solutions $A_{11}$ and $A_{22}$ will be determined from the fact that this solution must satisfy the boundary conditions (5). It will also be regarded 


\section{TPACEE-2016}

that the derivative of the Macdonald zero order function is equal to the Macdonald first order function, that is:

$$
\frac{d K_{0}(v r)}{d r}=-v K_{1}(v r)
$$

After using the solution (23) in the equations describing the boundary conditions, we obtain:

$$
\begin{aligned}
& A_{11} \frac{d K_{0}\left(v_{1} r\right)}{d r}+N A_{22} \frac{d K_{0}\left(v_{2} r\right)}{d r}=p_{11} t_{10}+p_{12} t_{20}+q_{1}+p_{11} A_{11} K_{0}\left(v_{1} r\right)+p_{11} N A_{22} K_{0}\left(v_{2} r\right)+ \\
& +p_{12} M A_{11} K_{0}\left(v_{1} r\right)+p_{12} A_{22} K_{0}\left(v_{2} r\right) ; \\
& M A_{11} \frac{d K_{0}\left(v_{1} r\right)}{d r}+A_{22} \frac{d K_{0}\left(v_{2} r\right)}{d r}=p_{21} t_{10}+p_{22} t_{20}+q_{2}+p_{21} A_{11} K_{0}\left(v_{1} r\right)+p_{21} N A_{22} K_{0}\left(v_{2} r\right)+ \\
& +p_{22} M A_{11} K_{0}\left(v_{1} r\right)+p_{22} A_{22} K_{0}\left(v_{2} r\right) ;
\end{aligned}
$$

By grouping terms beside unknown values $A_{11}$ and $A_{22}$ we obtain:

$$
\begin{aligned}
& A_{11}\left(-v_{1} K_{1}\left(v_{1} r_{0}\right)-p_{11} K_{0}\left(v_{1} r_{0}\right)-p_{12} M K_{0}\left(v_{1} r_{0}\right)\right)+A_{22}\left(-N v_{2} K_{1}\left(v_{2} r_{0}\right)-p_{11} N K_{0}\left(v_{2} r_{0}\right)-\right. \\
& \left.-p_{12} K_{0}\left(v_{2} r_{0}\right)\right)=p_{11} t_{10}+p_{12} t_{20}+q_{1} ; \\
& A_{11}\left(-M v_{1} K_{1}\left(v_{1} r_{0}\right)-p_{21} K_{0}\left(v_{1} r_{0}\right)-p_{22} M K_{0}\left(v_{1} r_{0}\right)\right)+A_{22}\left(-v_{2} K_{1}\left(v_{2} r_{0}\right)-p_{21} N K_{0}\left(v_{2} r_{0}\right)-\right. \\
& \left.-p_{22} K_{0}\left(v_{2} r_{0}\right)\right)=p_{21} t_{10}+p_{22} t_{20}+q_{2} .
\end{aligned}
$$

If we introduce new designations, then (26) can be rewritten in a shorter form:

$$
\begin{aligned}
& A_{11} P_{11}+A_{22} P_{12}=Q_{1} ; \\
& A_{11} P_{21}+A_{22} P_{22}=Q_{2},
\end{aligned}
$$

where new designations were obtained by substituting the values $r=r_{0} \mathrm{~B}(26)$.

$$
\begin{aligned}
& P_{11}=-v_{1} K_{1}\left(v_{1} r_{0}\right)-p_{11} K_{0}\left(v_{1} r_{0}\right)-p_{12} M K_{0}\left(v_{1} r_{0}\right) \\
& P_{12}=-N v_{2} K_{1}\left(v_{2} r_{0}\right)-p_{11} N K_{0}\left(v_{2} r_{0}\right)-p_{12} K_{0}\left(v_{2} r_{0}\right) \\
& P_{21}=-M v_{1} K_{1}\left(v_{1} r_{0}\right)-p_{21} K_{0}\left(v_{1} r_{0}\right)-p_{22} M K_{0}\left(v_{1} r_{0}\right) \\
& P_{22}=-v_{2} K_{1}\left(v_{2} r_{0}\right)-p_{21} N K_{0}\left(v_{2} r_{0}\right)-p_{22} K_{0}\left(v_{2} r_{0}\right) \\
& Q_{1}=p_{11} t_{10}+p_{12} t_{20}+q_{1} ; \\
& Q_{2}=p_{21} t_{10}+p_{22} t_{20}+q_{2} .
\end{aligned}
$$

Thus, the values of the unknown coefficients that determine the solution of this problem can be represented as follows:

$$
\begin{aligned}
& A_{11}=\frac{Q_{1} P_{22}-Q_{2} P_{12}}{P_{11} P_{22}-P_{12} P_{21}} ; \\
& A_{22}=\frac{Q_{2} P_{11}-Q_{1} P_{21}}{P_{11} P_{22}-P_{12} P_{21}} .
\end{aligned}
$$

If we use the identical equation for Bessel functions:

$$
\frac{d\left(r^{n} K_{n}(r)\right)}{d r}=r^{n} K_{n-1}(r),
$$




\section{TPACEE-2016}

then we can present the final form of the equation for the heat flow outgoing, for example, from the inner surface of building envelope:

$$
\begin{gathered}
Q=\int_{0}^{2 \pi} d \varphi \int_{r_{0}}^{r_{1}} \alpha_{i n}\left(t_{\text {in }}-t_{1}\right) r d r, \text { or } \\
Q=2 \pi \int_{r_{0}}^{r_{1}} \alpha_{i n}\left(t_{i n}-t_{10}-A_{11} K_{0}\left(v_{1} r\right)-N A_{22} K_{0}\left(v_{2} r\right)\right) r d r
\end{gathered}
$$

Using the relation of the following type:

$$
\frac{d\left(v_{1} r K_{1}\left(v_{1} v r\right)\right)}{d\left(v_{1} r\right)}=-v_{1} r K_{0}\left(v_{1} r\right)
$$

equation for $Q$ can be presented as follows, after the integral is taken over the length:

$$
\begin{aligned}
& Q=2 \pi \alpha_{i n}\left((t-t)\left(\frac{r_{1}^{2}-r_{0}^{2}}{2}\right)-\left(\frac{A_{11}}{v_{1}}\left(r_{1} K_{1}\left(v_{1} r_{1}\right)-r_{0} K_{1}\left(v_{1} r_{0}\right)\right)+\right.\right. \\
& \left.+\frac{A_{22} N}{v_{2}}\left(r_{1} K_{1}\left(v_{2} r_{1}\right)-r_{0} K_{1}\left(v_{2} r_{0}\right)\right)\right) .
\end{aligned}
$$

To confirm that developed technique works, a series of experiments was conducted and obtained data were processed.

\section{Results}

For the experiment a $1000 \times 1000 \mathrm{~mm}$ panel fragment was taken, in the center of which a metal rod (rod diameter varied) was installed. The panel was attached to a bore of the climate chamber with the retaining fasteners. REOCAMTCM-1000 climate chamber was used. General view of the chamber is shown in Figure 2. [6,10,15]

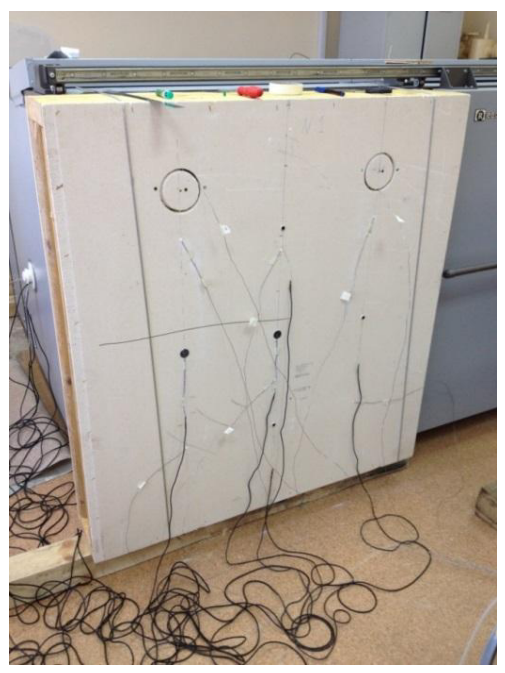

Fig.2. General view of the climate chamber with a fragment of the panel.

To create a hermetically sealed space inside the climate chamber, the perimeter of the chamber bore was treated with a sealant. After that the panel fragment with thermally 


\section{TPACEE-2016}

conductive inclusion was attached to the chamber bore with the help of retaining fasteners. Imperviousness in the chamber was controlled by a pressure gauge 516.11 (accuracy class 0.15). Measurement design is shown in Figure 3.

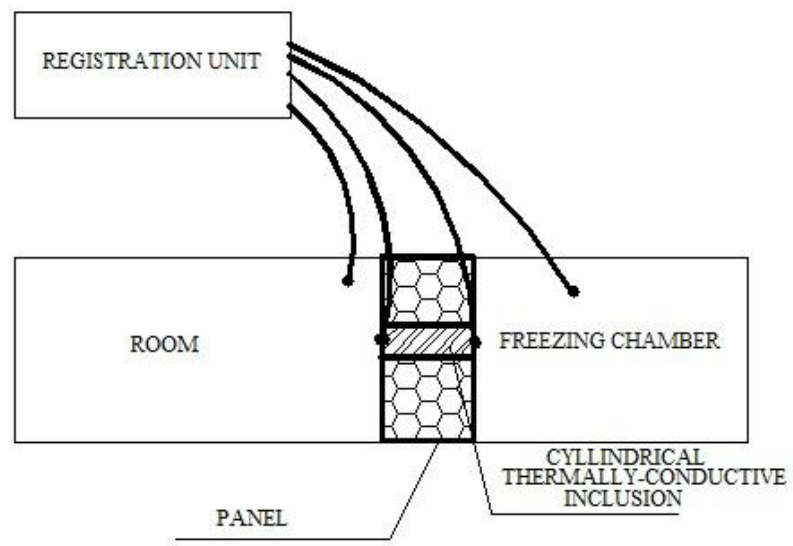

Fig. 3. Circuit diagram of measurement.

For measuring the temperature at the distinguished points the copper-constantan thermocouples were used as defined in GOST 50431-92 standard. A microammeter M903/1 was used as a secondary device. Total amount of the thermocouples installed for the experiments was 5 . Thermocouple measurement accuracy $-0.1{ }^{\circ} \mathrm{C}$.

Results of the experiment and calculations are shown in Table 1.

Initial data for the calculations:

1. Indoor air temperature $\mathrm{t}_{\text {in }}=16 ; 17 ; 18 ; 20^{\circ} \mathrm{C}$;

2. Outdoor air temperature $\mathrm{t}_{\text {out }}=-20 ;-30 ;-35 ;-46^{\circ} \mathrm{C}$;

3. Coefficient of heat transfer of the building envelope inner surface $\alpha_{\mathrm{in}}=8.7 \mathrm{~W} /\left(\mathrm{m}^{20} \mathrm{C}\right)$;

4. Coefficient of heat transfer of the building envelope outer surface $\alpha_{\text {out }}=23.2$ $\mathrm{W} /\left(\mathrm{m}^{20} \mathrm{C}\right)$;

5. Thermal resistance of the insulator material $\mathrm{R}=0,00057\left(\mathrm{~m}^{20} \mathrm{C}\right) / \mathrm{W}$;

6. Thermal resistance of the thermally-conductive inclusion $\mathrm{R}_{0}=1.923\left(\mathrm{~m}^{20} \mathrm{C}\right) / \mathrm{W}$;

7. Thickness of lining $\delta_{1}=\delta_{2}=0.001 \mathrm{~m}$;

8. Thermal conductivity coefficient of lining $\lambda=175 \mathrm{~W} /\left(\mathrm{m}^{\circ} \mathrm{C}\right)$;

9. Radius of thermally-conductive inclusion $\mathrm{r}_{0}=8 ; 10 ; 12 ; 16 ; 20 \mathrm{~mm}$.

Table 1. Results of the experiment and calculations

\begin{tabular}{|c|c|c|c|c|c|c|c|}
\hline \multirow[b]{2}{*}{$\mathrm{N}$} & \multirow[b]{2}{*}{$\begin{array}{c}\text { Rod } \\
\text { diamet } \\
\text { er, } \\
\mathrm{mm}\end{array}$} & \multirow[b]{2}{*}{$\begin{array}{l}\text { Indoor air } \\
\text { temperatu } \\
\text { re tin, }{ }^{\circ} \mathrm{C}\end{array}$} & \multirow[b]{2}{*}{$\begin{array}{l}\text { Outdoor } \\
\text { air } \\
\text { temperat } \\
\text { ure tout, } \\
{ }^{\circ} \mathrm{C}\end{array}$} & \multicolumn{2}{|c|}{ In practice } & \multicolumn{2}{|c|}{ In theory } \\
\hline & & & & $\begin{array}{l}\text { Temperatur } \\
\text { e at the } \\
\text { outer end of } \\
\text { the rod } \\
\text { t } 2,{ }^{\circ} \mathrm{C}\end{array}$ & $\begin{array}{c}\text { Temperat } \\
\text { ure at the } \\
\text { inner end } \\
\text { of the rod } \\
\mathrm{t} 1,{ }^{\circ} \mathrm{C}\end{array}$ & $\begin{array}{c}\text { Temperat } \\
\text { ure at the } \\
\text { outer end } \\
\text { of the rod } \\
\mathrm{t} 2,{ }^{\circ} \mathrm{C}\end{array}$ & $\begin{array}{l}\text { Temperat } \\
\text { ure at the } \\
\text { inner end } \\
\text { of the rod } \\
\mathrm{t} 1,{ }^{\circ} \mathrm{C}\end{array}$ \\
\hline 1 & 8 & 18 & -30 & -19.2 & 11.2 & -22.0 & 8.9 \\
\hline 2 & 10 & 18 & -30 & -17.9 & 8.9 & -20.1 & 6.5 \\
\hline 3 & 12 & 18 & -30 & -16.3 & 6.8 & -18.4 & 4.5 \\
\hline 4 & 16 & 18 & -30 & -13.9 & 3.5 & -16 & 1.4 \\
\hline 5 & 20 & 18 & -30 & -12.3 & 1.5 & -14.4 & -0.8 \\
\hline 6 & 8 & 17 & -46 & -32.9 & 7.2 & -35.1 & 4.9 \\
\hline 7 & 10 & 17 & -46 & -30.2 & 4.2 & -32.6 & 1.9 \\
\hline 8 & 12 & 17 & -46 & -28 & 1.6 & -30.5 & -0.8 \\
\hline 9 & 16 & 17 & -46 & -24.8 & -2.4 & -27.3 & -4.8 \\
\hline
\end{tabular}




\begin{tabular}{|c|c|c|c|c|c|c|c|}
\hline 10 & 20 & 17 & -46 & -23.0 & -5.4 & -25.2 & -7.6 \\
\hline 11 & 8 & 16 & -20 & -11.7 & 11.4 & -14.01 & 9.1 \\
\hline 12 & 10 & 16 & -20 & -10.3 & 9.7 & -12.54 & 7.4 \\
\hline 13 & 12 & 16 & -20 & -9.0 & 8.2 & -11.31 & 5.9 \\
\hline 14 & 16 & 16 & -20 & -7.2 & 5.8 & -9.5 & 3.5 \\
\hline 15 & 20 & 16 & -20 & -6.0 & 4.2 & -8.3 & 1.9 \\
\hline 16 & 8 & 20 & -35 & -23.5 & 11.8 & -25.9 & 9.5 \\
\hline 17 & 10 & 20 & -35 & -21.4 & 9.2 & -23.6 & 6.8 \\
\hline 18 & 12 & 20 & -35 & -19.5 & 6.9 & -21.7 & 4.5 \\
\hline 19 & 16 & 20 & -35 & -16.6 & 3.2 & -18.9 & 1 \\
\hline 20 & 20 & 20 & -35 & -14.8 & 0.8 & -17.1 & -1.5 \\
\hline
\end{tabular}

\section{Conclusion}

In course of the theoretical studies by means of mathematical physics methods we obtained analytical equations of temperature field distribution around the through cylindrical thermally-conductive inclusion in the light building envelopes of block boxes.

The analysis of the experimental data and the data obtained by the developed and refined physical-mathematical model of a stationary heat transfer through the building envelope, shows that the difference between the data varies between $10 \%$ and $25 \%$, which proves the accuracy of the developed model.

\section{References}

1. A.I. Kruglova, Klimat i ograzhdayushchie konstruktsii (Stroyizdat, Moscow, 1990)

2. Yu.P. Batalin, V.G. Chirskov, G.I. Shmal, Komplektno-blochnoe stroitel'stvo ob"ektov neftyanoy i gazovoy promyshlennosti (Nedra, Moscow, 1996)

3. Yu.P. Batalin, S.N. Vasserman, Ya.N. Kagan, V.L. Trofimov, Inzhenerno-stroitel'nye osobennosti zastraivaemykh territoriy neftegazodobyvayushchikh rayonov Zapadnoy Sibiri (Moscow, 2001)

4. A.Sh. Dekhtyar, Oblegchennye konstruktsii metallicheskikh sten promyshlennykh zdaniy (Stroyizdat, Moscow, 2009)

5. F.F. Tamplon, Metallicheskie ograzhdayushchie konstruktsii dlya zdaniy, vozvodimykh $v$ surovykh klimaticheskikh usloviyakh (Stroyizdat, Moscow, 2008)

6. K.V. Afonin, Sbornik materialov nauchno-prakticheskoy konferentsii prepodavateley, molodykh uchenykh, aspirantov TyumGASA, 3-6 (2002)

7. A.I. Gorkovenko, T.S. Zhilina, V.S. Starikov, Stroitel'ny vestnik Tyumenskoy oblasti, 4, 48-51 (1999)

8. A.I. Gorkovenko, T.S. Zhilina, Oil and gas, 1, 108-112 (2000)

9. K.V. Afonin, A.F. Shapoval, K.N. Ilyukhin, M.N. Chekardovskiy, Sbornik dokladov nauchno-prakticheskoy konferentsii, 487-491 (2000)

10. T. Zhilina, Applied Mechanics and Materials, 729, 224-228 (2015)

11. V.N. Bogoslovsky, Stroitel'naya teplofizika (Stroyizdat, Moscow, 2013)

12. V.N. Bogoslovsky, Teplovoy rezhim zdaniya (Stroyizdat, Moscow, 1999)

13. B.G. Aksenov, Stefurak, Matematika (RIO TyumGASU, Tyumen, 2013)

14. L.Z. Rumshinskiy, Matematicheskaya obrabotka rezul'tatov eksperimenta (Nauka, Moscow, 1971)

15. I.Yu. Shalagin, Inzhenernyy vestnik dona magazine, 2-2, (2015)

16. N.I. Kurilenko, G.Ya. Mamontov, L.Yu. Mikhaylova, EPJ Web of Conferences, 82, (2015)

17. G.V. Kuznetsov, N.I. Kurilenko, V.I. Maksimov, G.Ya. Mamontov, Journal of Engineering Physics and Thermophysics, 86, 519-524 (2013) 